\title{
KULTURA PAMĆENJA U ROMANU BAŠTA, PEPEO DANILA KIŠA
}

\begin{abstract}
Ove godine navršava se pedeset pet godina od izlaska iz štampe prvog Kišovog romana Bašta, pepeo. Biografski roman, djelo „o sudbinama zaboravljenih od rođenja”, postao je sastavni dio trilogije koja je iste temantske strukture i koja se ne uči nego se naslijeđuje. Biografija je kod Kiša realnost i fantastika, percepcija vječne potrebe da se prošlost sačuva od zaborava. Budući da riječi velikih pisaca imaju iskustvo, nema sumnje da su Kišove riječi trajne u kuturi pamćenja srpske i svjetske literature.

Ključne riječi: Danilo Kiš, Bašta, pepeo, biografija, djetinstvo, Eduard Sam, kultura pamćenja
\end{abstract}

Prije pedeset pet godina izašao je iz štampe roman Bašta, pepeo, koji je od strane kritičara ocijenjen kao remek-djelo i bio preveden na više svjetskih jezika. Danilo Kiš je već bio autor Mansarde i Psalma 44, koji su objavljeni zajedno u istim koricama 1962. godine; prvo djelo je satirična poema pisana u prvom licu, a drugo u trećem licu, sa temom o koncentracionom logoru i sudbini Jevreja u Drugom svjetskom ratu.

Bašta, pepeo, sa romanima Rani jadi (1970) i Peščanik (1972), dio je trilogije porodičnog ciklusa koji nosi zajednički naziv Bildungsroman. Naracija romana Bašta, pepeo već na početnim stranicama evocira Prustov „ljubičasti oreol” i, snagom neusporedivog lirskog tona, govori o ,iščezavanju ljudi”.

Dječak, Andreas Sam, koji prefigurira samog pisca, saznavši od majke da mu je umro ujak, kojega nije poznavao, počinje da razmišlja o ,tajni smrti”, i o tome da će i njegova parodica: majka, otac i sestra Ana, jednog dana morati da umru.

Kad je to „blesnulo nekim ljubičastim sjajem” (Kiš 1969: 15), počeo je da se moli Bogu i da vjeruje u besmrtnost sebe i svojih najbližih. Jedan od načina da spriječi ,naglo padanje crne svile” (Kiš 1969: 19), i da bi mogao da zaspi, Andreas Sam pokušava da realnost vidi ironično, počinje da broji do šezdeset, zatim do

*ssmitran@unite.it 
dvjesta da bi, kako kaže, mogao budan da svjedoči dolazak smrti i da je prevaziđe: „Hteo sam, velim, da svesno prisustvujem dolasku sna, iz straha i radoznalosti, kao što sam bio rešio da ću jednog dana svesno prisustvovati dolasku smrti i time je pobediti" (Kiš 1969: 27).

Andreas Sam, unosi u pripovijedanje lirsko sjećanje na svog oca Eduarda Sama, koji ga više neće napustiti: „Zavijen plavim dimom svoje simfonije, zakrvavljenih očiju, nervozan i pripit, genije putovanja, Ahasver, on je ličio na pesnika koji izgara u stvaralačkom zanosu" (Kiš 1969: 23). U dopuni će napisati da je otac tada radio na „trećem ili četvrtom izdanju jedne od svojih, svakako najpoetičnijih knjiga, na svojim putopisima, na u to vreme čuvenom Kondukteru autobuskog, brodskog, železničkog i avionskog saobraćaja" (Kiš 1969: 23).

Kiš nas upoznaje sa svojim vremenom, u kojem je dominantan intelektualni lirizam samosvojne duše koja traga za identitetom pripadnosti koja ga odvodi u prošlost, a on se hvata za sadašnjost. Ono u što je jedino siguran, to su odabrane misli: „Za one koji više nemaju domovine, baš i pisanje može biti jedna vrsta prebivališta" (Adorno 1994: 94).

Karakterizacija očevih poroka i negativnih osobina detaljno su opisane i, bez komentara, prolaze kroz vrijeme i prostor, kao nešto sudbinski dato. Zato ništa kod oca nije za kritiku, ni kad bude suspendovan sa posla kao željeznički radnik: „Uskoro je postao poznat u celoj županiji kao opasan revolucionar-anarhista, pesnik i neurastenik, ali i poštovan u izvesnim krugovima zbog svoje garderobe, geroka, štapa i šešira, zbog svojih deliričnih solilokvija punih rečitosti, kao i zbog svog prodornog glasa koji je ulivao respekt" (Kiš 1969: 109-110).

Otac je umjetnik, pripovjedač, veliki pijanac, prorok, prirodnjak - autor jugoslovenskog i međunarodnog željeznićkog Reda vožnje tramvajskih, pomorskih, željezničkih $i$ vazdušnih komunikacija, pisanog 1939. godine - koga je u drugom izdanju namjeravao da proširi na čitavu kuglu zemaljsku. Kiš je mnogo godina kasnije rekao, da je taj očev „Red vožnje talmudska knjiga: komentar” (Kiš 1990a: 20).

Eduard Sam nije za sina negativan zato što je ,alkoholičar, neurastenik, Jevrejin" (Kiš 1990a: 18), već zato što je odsutan. Ta praznina koju je ispunilo sjećanje na oca je, ujedno, i priča o sebi i o prohujalom djetinstvu.

Tako su sve ostale karakteristike oca koje kroz priču otkriva, i čiji broj raste iz stranice u stranicu, samo „materijal za književni lik”. Andreas Sam se plaši za oca i osjeća svoju odgovornost naslijednika: on je duhovni testament očevih i majčinih predaka koje stalno u sebi preispituje. To, sartrovski rečeno ,podmuklo djelovanje biografije" (Kiš 1974: 122) je, okvirno rečeno, stilska konkretnost u koju Kiš unosi svoju tehniku pisanja lirskog subjektivizma i zamaha. U ovo se ubraja i jedna pouka, jedan edukacijski aspekt, kada, Eduard Sam, u jednom rijetko lucidnom trenutku svog beznađa, govori sinu: „Moja uloga žrtve, koju sam igrao s manje-više uspeha celog života - jer čovek zapravo igra svoj život, svoju sudbinu - ta uloga se, velim, polako privodi kraju. Ne može se, mladiću moj, i to zapamti jednom zauvek, ne može se igrati celog života uloga žrtve a da se konačno i ne postane žrtvom" (Kiš 1969: 122). 
Ako nije ispovijest, onda je ovo melanholični trenutak života koji dolazi iz prošlosti i kojim se Kiš, definitivno, deklariše: u pripovijedanju nije slučajno ono što je u biografiji važno. Preplitanje istorijskog i narativnog diskursa, u meandrima introspekcije u kojoj se prepoznaje istorija holokausta, oblik su kulturnog pamćenja i inspirativno neponovljiv Kišov kod i zavjet pamćenja. Doživljeno se oblikuje jezikom, u kome se emocije sažimaju sa istorijskim protokom.

Za sebe Andreas Sam kaže: „Ja sam još od detinjstva imao neku bolesnu preosetljivost i moja je mašta brzo pretvarala sve u uspomenu, čak suviše brzo: katkada je bio dovoljan jedan dan, razmak, razmak od nekoliko sati, obična promena mesta, pa da jedan svakidašnji događaj, čiju lirsku vrednost nisam osećao sve dok sam živeo s njim, postane odjednom ovenčan sjajnim ehom, kakvim se krunišu samo uspomene koje su dugo godina stajale u snažnom fiksiru lirskog zaborava" (Kiš 1969: 70).

Oblik samoispovijesti i jak lični pečat koji karakteriše lirsku prozu romana Bašta, pepeo doprinijela je da, u savremenoj srpskoj književnosti, Kiš postane najviše evropski i svjetski pisac. ${ }^{1}$ Kišova poetika ima biografsku paradigmu zasnovanu na tragičnom iskustvu, u kojoj se stvarnost prenosi pamćenjem i u kojoj nema iskoraka iz istorijksih činjenica. Pisana riječ kod Kiša nije samo informacija, ona ima svoje značenje, i objašnjenje, ime nekoga i naziv nečega, u njegovom djelu, treba čitati kao iskustvo riječi (S. Š.).

Uvijek akribično upotrebljene, riječi kod Kiša imaju moć pripovijedača koji svoje lično iskustvo identifikuje sa kolektivnim. Tako je njegov Eduard Sam lik oca i lik žrve Drugog svjetskog rata i žrtva svih pogroma čovječanstva koji i dalje traju. U romanu, Bašta, pepeo, kad je otac prestao da bude njegova sjena, to jest kad je očeva figura napustila pripovijedanje, sve se raspalo, ništa više nije imalo smisla: „Otkako je genijalna figura mog oca nestala iz ove priče, iz ovog romana - sve se rastočilo, razuzdalo. Njegova moćna pojava, njegov autoritet, pa čak i njegovo ime, njegovi slavni rekviziti, bili su dovoljni da drže potku priče u čvrstim okvirima [...]" (Kiš 1969: 193).

Ono što je napisano, bilo je važno u očevoj biografiji: bio je ,enciklopedista, mag, psiholog, itd.” (Kiš 1969: 187), ,genijalni mladić, vunderkind, pesnik i pijanista" (Kiš 1969: 203) i još mnogo toga što Kiš, iz stranice u stranicu, ponavlja samom sebi. U ovom kazivanju sad više nije pitanje šta je biografsko, kad znamo da se Kiš izjasnio kako nije moguće razdvojiti ,šta je stvarno a šta domišljeno u jednom djelu" (Kiš 1990b: 212), što je najviša forma književnosti - spajanje suprotnosti i njihova čvrsta povezanost.

Svaki put kad su se iznenada selili, i kad su ,stabla divljih kestenova ,iz njihove ulice iščezavala u mraku, otac nije bio trijezan. U toj asimetričnoj stvarnosti piščevo kazivanje služi se „,ironičnom distancom” koja je doprinijela da stil ne bude patetičan. Kiš hoće da se sačuva patrijarhalno naslijeđe u kojem je vaspi-

${ }^{1}$ „Tanana psihološka nijansiranja, lirske introspekcije i emotivni naboj Kišovog poetskog teksta deo su subjektivnog viđenja u kome se vizija izgubljenog oca, nesnalaženja, preosetljivosti, zamišljenosti i patosa, ovaploćuje kao traganje za korenima sopstvenog bića, za dalekim, davnim uspomenama, izgubljenim u moru podsvesti gde toplina ugašenog detinjstva postaje intelektualni nemir i literarna vokacija" (Palavestra 1998: 141). 
tan i nada se da će njegovo sjećanje uticati očevoj društvenoj rehabilitaciji. Brani identitet oca i svoj lični, pred golgotskom provalijom, u kojoj će, poslije vojvođanskog pokolja Jevreja i Srba, januara 1942. godine, njihova parodica otputovati kod očevih rođaka u Mađarsku, gdje će Eduard Sam sa mađarskim Jevrejima biti prognan u geto, i 1944. biti deportovan u Aušvic zajedno sa članovima njegove porodice, od kojih su neki od njih odvedeni u druge koncetracione logore i odakle se nisu vratili.

Milica Dragičević, majka² Danila Kiša krstila ga je sa sestrom Danicom u pravoslavnoj crkvi u Novom Sadu, što ih je spasilo deportacije. Kiš je vjerovao „da će u skoroj budućnosti, ako sve ne ode dođavola, odgovornost pisca biti odmeravana u prvom redu u odnosu na njegov stav prema stvarnosti logorà; jednih i drugih podjednako" (Kiš 1990a: 189). Mislio je na logore Aušvic i Kolimu.

To se svakako odnosi na kulturu pamćenja holokausta što, tematske afinitete njegovog djela oduvijek dovodi u vezu sa Borhesom, Nabokovim, Kunderom, Kestlerom, Šulcom, a u nekom smislu i sa Orvelom, i sa Andrićem i Krležom. Šulc i Babelj su odrasli u jevrejskoj tradiciji, a Kiš ju je, kako je sam rekao, proučavao u njemu dostupnoj literaturi.

Što se pak tiče uticaja ovih pisaca na Kiša, Josif Brodskij je u jednom svom govoru na Simpozijumu u Strazburu 1991. godine rekao: „Ipak uticaji po definiciji ustupaju pred talentom, tj. u odnosu na njega su druga violina. Svi smo čitali Babelja, Borhesa i Šulca, ali Danilo Kiš je napisao knjigu Bašta, pepeo" (Brodskij 2010: 5).

Kiš je, međutim, eksplicitirao da je Kestler jedan od njegovih učitelja i, pozivajući se na njega, objasnio svoje djelo: „Kada bih hteo da sažmem na najkraćem mogućnom prostoru ono saznanje koje sam stekao iskustvom, ličnim kao i civilizacijskim, dakle lektirom, saznanje koje čini kvintisenciju moga pisanja, onda bi se to moglo svesti na sledeće: u osmosi ljudskog iskustva ove dve u suštini kontradiktorne pozicije: pozicija ,jogija” i pozicija „komesara”. Pozicija ,jogija” jeste metafizički i ontološki status, obuzetost poslednjim pitanjima (života i smrti), a ona druga jeste pozicija društvenog bića, čoveka koji metafiziku svodi na sociologiju, nalazeći u društvrnom statusu totaliteta bića" (Kiš 1990b: 187).

Kod Kiša se ove dvije krajnosti prepliću u prozi „autobiografskog žanra” u kojima traži smisao života, pitajući se: „odakle sam?”, „ko sam?”, „kuda idem?”

Rečeno u širem smislu značenja, Kišova književna karijera govori o položaju individue u društvu u ekstremnim okolnostima za životni opstanak u kojima se čovjek ikad našao u istoriji čovječanstva. Nije to samo, ,jedan akt protesta”, kako Starobinski sintetizuje status i ulogu pisca, kod Kiša je porodično-autobiografska tragedija holokausta postala materijal za pisanje.

Književnost se, kao što je poznato, kod pisca javlja još u djetinstvu, kao potreba da zapiše ono što doživljava, jer samo što je zapisano to je i doživljeno. Ovaj aspekt Brodskij je u pomenutom eseju posebno istakao kod Kiša, definišući ga ,pjesnikom”, a njegovu prozu, „faktura njegove rečenice, poezija”: „Kišovo

\footnotetext{
${ }^{2}$, ,Što se tiče majke, i u stvaranju njenog lika preovlađuju, čini mi se, pre književni nego psihološki razlozi. Majka je pozitivn junak, i s toga nisam mogao na nju da primenim u punoj meri blagotvornu ironičnu distancu. Ljubav je odveć patetična, kao i lepota i patnja” (Kiš 1990a: 19).
} 
osjećanje istorije veoma je lično, a osjećanje lične istorije tragično javno. I jedno i drugo posmatrano kroz isto sočivo."

Mnogostruka evropska polimorfičnost nije udaljila Kiša od svoga podneblja - balkanskog i mitelevropskog - samo je, ako je moguće, potencirala njegovo interesovanje za njih i za njegovo mjesto u tradiciji u kojoj je rođen. Za Kiša Istorija je rat, to jest, Istorija je iskustvo koje se nasljeđuje. Dramatičnost Istorije u Kišovoj poetici pisanja, kontraponira se ironiji, jedna drugom se objašnjavaju i pregnantno djeluju na pamćenje.

Pamćenje nije jedna tehnika kojoj se uči, pamćenje se, kao i Istorija, kod njegovog naroda nasljeđuje. Razlog što se Kišovo djelo danas definiše kao sukob individualnog i kolektivnog iskustva - odnosi se prevashodno na predratna politička strujanja i poslijeratnu ljevicu na vlasti, možda samo iziskuje odgovor na pitanje: da li se Kiš danas može smatrati poslednjim piscem bivše Jugoslavije, poslije Andrića, Crnjanskog i Krleže?

U prvom redu vidi se jasno da je karakteristika Kišovog pamćenja jedna dvostrana medalja, stvarnosti i fikcije koje se isprepliću i koje, u naraciji, imaju isti efekat. Individualnost Kišovog pamćenja doseže u dubine autobiografske prošlosti, a njegovo enciklopedijsko znanje je ušlo u magične krugove sveopšte kulture pamćenja.

U jednom televizijskom intervjuu Kiš je sjećanje na oca, na Eduarda Sama, povezao sa tankim nitima biografske literature: „Moj otac je rođen u zapadnoj Mađarskoj, koja je u to vreme bila u sastavu Dvojne monarchije. Valjda u želji za integracijom, svoje je ime mađarizovao kada mu je bilo trinaest godina. Trgovačku akademiju završio je u Zalaegersegu, rodnom mestu gospodina Viraga, koji će, milošću gospodina Džojsa, postati poznat pod imenom Bloom, Leopold Bloom" (Kiš 1990a: 24).

Putovanje u sjećanje jeste prije svega očeva biografija koju pisac dovodi do književnih koincidencija koje su, samo još jedan dokaz, neponovljivosti, pojedinačno svake ljudske sudbine ili, kako kaže Brodskij, ,pisanje biografije znači otimanje čovjeka zaboravu, kao što je davanje života čovjeku njegovo otimanje nepostojanju" (Brodskij 2010: 5).

Prozreti u Kišovu „pesimističku koncepciju literature” (definicija je piščeva), vodi, svakako, ka jednom razmišljanju na koje ni naša posthumana epoha nije još našla odgovor. Književna istorija će se baviti i iznalaziti interpretativna rješenja ovakve lirske proze koja, po mišljenju filozofa Agambena, snagom svoje introspekcije predstavlja samog pisca „kao epigonalno biće koje postoji u odnosu na druge" (Agamben 2017: 42).

$\mathrm{U}$ krajnjoj istanci, stoga, u svim autobiografijama, i u Kišovom romanu $\mathrm{Ba}$ šta, pepeo, „kao i u svakom životu - mrtvi i živi su saživljeni, tako su bliski i zahtjevni da nije jednostavno razlučiti u kojoj je mjeri prisustvo jednih i drugih različito" (Agamben 2017: 165). Činjenica je, međutim, da u našoj epohi kultura pamćenja sve više zavisi od hronike i sve manje od istorije pa se, na njenu dugotrajnost i ne može računati.

U savremenoj ideologiji banalnosti individuanog pamćenja nema mjesta za kolektivno pamćenje, čime se ono po prirodi stvari, samo od sebe briše i nestaje bez traga. Zato je roman Bašta, pepeo, ne samo iskonski model najličnijeg pamćenja nego i pamćenje svih ,zaboravljenih sudbina od rođenja”. 


\section{ЛИТЕРАТУРА}

Adorno 1994: T. W. Adorno, Minima moralia, Torino: Emaudi.

Agamben 2017: G. Agamben, Autoritratto nello studio, Milano: Nottetempo.

Brodskij 2010: J. Brodskij, Predavanje o Danilu Kišu, Književne novine, 1. mart-

1. april 2010 (iz J. Brodskij, Wyklad o Danilu Kišu, Zeszyzy Literackie, 2009/4, p. XXVII, 110-112).

Kiš 1969: D. Kiš, Bašta, pepeo, Beograd: Prosveta.

Kiš 1974: D. Kiš, Poetika, knjiga druga, Beograd: Mala edicija ideja, Predsedništvo konfederacije studenata Jugoslavije.

Kiš 1990a: D. Kiš, Život, literatura, Sarajevo: Svjetlost.

Kiš 1990b: D. Kiš, Homo poeticus, Sarajevo: Svjetlost.

Palavestra 1998: P. Palavestra, Jevrejski pisci u srpskoj književnosti, Beograd: Institut za književnost i umetnost.

Stevka S. Šmitran

\section{LA CULTURA DEL RICORDO NEL ROMANZO GIARDINO, CENERE \\ DI DANILO KIŠ}

\section{Riassunto}

Quest'anno sono cinquantacinque anni dall'uscita del romanzo Giardino, cenere di Danilo Kiš. Romanzo autobiografico, opera ,sul destino dei dimenticati dalla nascita”, fa parte della trilogia dalla stessa struttura tematica, che non si impara ma si eredita. La biografia in Kiš è realtà e finzione, percezione dell'eterna necessità di salvare il passato dall'oblio. Poiché le parole dei grandi scrittori hanno l'esperienza", non c'è dubbio che le parole di Kiš restano pietre miliari nella cultura del ricordo della letteratura serba e mondiale. 